\title{
Decarburization of Molten Iron with Oxidizing Gases and Oxidation of Coexisting Metallic Elements*
}

\author{
By Kōin Itō ${ }^{* *}$ and Kōkichi Sano**
}

\begin{abstract}
Synopsis
The rates of decarburization were measured on molten $\mathrm{Fe}-\mathrm{C}$ and $\mathrm{Fe}-$ $\mathrm{C}-\mathrm{Me}$ alloys with $\mathrm{H}_{2} \mathrm{O}-\mathrm{Ar}$ and $\mathrm{CO}_{2}-\mathrm{Ar}$ mixtures. The oxidation rates of coexisting metallic elements were also measured. Before an oxide phase appears on the surface of melt, rates of decarburization were proportional to the partial pressure of oxidant gas component. The alloying elements did not affect the rate of decarburization. Apparent activation energies of these reactions were found to be $5.5 \pm 3$ and $6 \pm 2$ kcal for $\mathrm{H}_{2} \mathrm{O}-\mathrm{Ar}$ and $\mathrm{CO}_{2}-\mathrm{Ar}$ mixtures, respectively. Accordingly, the reaction in the highcarbon content range seems to be controlled by the rate of transfer of the oxidant component from bulk of gas to the surface of melt. The carbon concentration where oxide appears on the surface of melt, $[\mathrm{C}]_{f}$, is proportional to the partial pressure of oxidant gas component, and varied with the species of the gas and the alloying elements. The rate of decarburization for carbon concentration above $[\mathrm{G}]_{f}$ was analyzed by the rate equation which was derived from the rate of diffusion of the oxidant gas component. The variations of $[\mathrm{C}]_{f}$ can be explained by an equation which was derived from the rate of transfer of gas component and those of carbon and oxygen in the melt. An explanation was tried thermodynamically on the difference between the values of $[\mathrm{C}]_{f}$ in the present work and in the converter steelmaking.
\end{abstract}

\section{Introduction}

In connection with the steelmaking reactions, there have been many works on the kinetics of decarburizations of molten iron with gases. Most of them were carried out by using oxygen gas diluted with argon, nitrogen, or other inert gases as the oxidizing gas. Various models were proposed on the reaction mechanism for the decarburization without slag. These models suggested that the rate determining step is to be mass transfers in gas phase for the carbon content greater than a critical value and changes to carbon transfer in the melt for carbon contents less than the critical value. The activation energy of reaction was found to be 13 to $35 \mathrm{kcal} / \mathrm{mole},{ }^{1), 2)}$ but these values are thought to be too large for the mass transfer process.

The authors had studied previously the decarburization of molten iron using $\mathrm{H}_{2} \mathrm{O}$-Ar mixtures in order to clarify its mechanism more accurately by making use of the extremely weak oxidizability of $\mathrm{H}_{2} \mathrm{O}$. The activation energy obtained was $5.5 \pm 3 \mathrm{kcal} / \mathrm{mole} .{ }^{3)}$ In the same paper, the authors had proposed a model of the reaction with successful explanation of the experimental results. Thereafter, the activation energies of reactions of this type have been reported in several papers as a few kilocalories. ${ }^{4)}$ There are still many discrepancies among the models of the mechanism, but the differences of experimental results may be due to each measurement condition. The authors also studied on the relations between decarburization with $\mathrm{CO}_{2}$-Ar mixtures and oxidation of coexisting metallic elements during the decarburization in order to confirm the validity of the previous postulations. In this paper, the authors will summarize the major points of their previous papers.

\section{Experimental}

\section{Apparatus}

A schematic diagram of the apparatus used is shown in Fig. 1. It consisted of two parts, one being a combination of equipments for purification of $\mathrm{H}_{2}, \mathrm{CO}_{2}$, and $\mathrm{Ar}$, and of a water vapor saturater, and the other the reaction furnace. The saturater consisted of a water-filled bottle as a preliminary saturater and an accurate saturater dipped in the constant-temperature water bath. A $40 \mathrm{~mm}$ ID and $50 \mathrm{~mm}$ depth recrystallized magnesia or electro-fused zirconia crucible containing $300 \mathrm{~g}$ of electrolytic iron was placed in a $80 \mathrm{~mm}$ ID quartz reaction tube surrounded by an induction coil. A $430 \mathrm{kC} \mathrm{H.F.} \mathrm{generater} \mathrm{was} \mathrm{used} \mathrm{as} \mathrm{the} \mathrm{power}$ source. Reacting gases were passed through a $9 \mathrm{~mm}$ ID alumina preheating tube (about $1200^{\circ} \mathrm{G}$ ) which was fixed below the water-cooled brass cap, and blown into the reaction crucible. The lower end of the preheating tube was kept apart from the metal surface by about $7 \mathrm{~mm}$, in order that the gas stream upon the surface of melt would be always constant.

\section{Operation}

In a typical experiment, $300 \mathrm{~g}$ of electrolytic iron was melted in a pure argon atmosphere and was re-

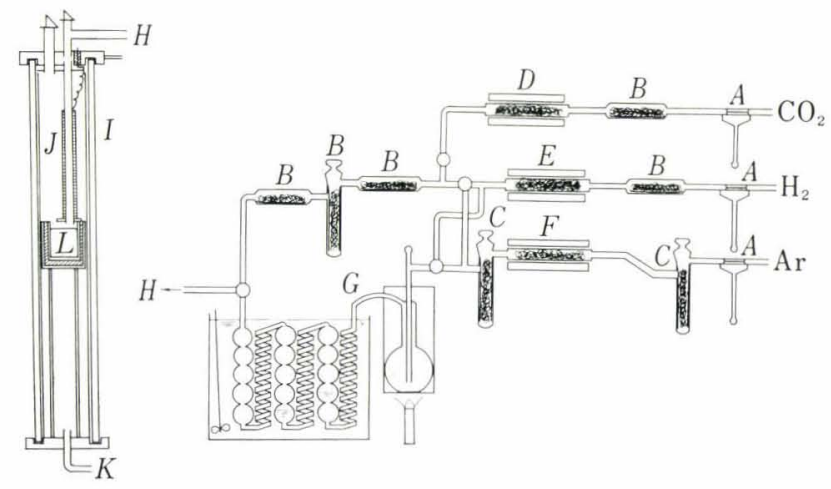

$A$ : flowmeter, $B: \mathrm{P}_{2} \mathrm{O}_{5}, C$ : soda asbestos,

$D$ : Cu net furnace, $E:$ Pt-asbestos furnace,

$F$ : Mg furnace, $G$ : steam saturater, $H$ : gas inlet,

$I$ : reaction tube, $J$ : preheater tube, $L:$ melt,

$K$ : gas outlet

Fig. 1. Schema of experimental apparatus

* Received December 1, 1967.

** Department of Metallurgy, Faculty of Engineering, Nagoya University, Chigusa-ku, Nagoya 464. 
duced at $1600^{\circ} \mathrm{C}$ sufficiently with $\mathrm{H}_{2}-\mathrm{Ar}(1: 1)$ mixture for $1.5 \mathrm{hr}$. Again atmosphere was replaced by pure argon in order to remove the dissolved hydrogen, and then carbon and some alloying element were added to the molten iron to make an alloy of desired composition. Holding the molten iron at the constant temperature, the decarburization reaction started by replacing the atmosphere by the oxidizing gas mixture. During the reaction, every 5 to $7 \mathrm{~g}$ of iron were pumped out several times with suitable intervals by $3 \mathrm{~mm}$ ID quartz tube and cooled quickly for analysis. Analysis of each component was done respectively according to the JIS methods. (JIS means Japanese Industrial Standard.) Temperature of molten iron was measured with an optical pyrometer calibrated by Pt5Rh/Pt20Rh thermocouple.

\section{Experimental Results}

At the temperatures of $1560^{\circ}, 1600^{\circ}$, and $1660^{\circ} \mathrm{C}$, molten iron-carbon alloys were decarburized with various $\mathrm{H}_{2} \mathrm{O}$-Ar mixtures. Gas mixtures were prepared by blowing argon at constant flow rate, $1700 \mathrm{~cm}^{3} / \mathrm{min}$, into the water vapor saturater. Some of the results are shown in Fig. 2, in which carbon concentration decreased linearly in each case until carbon concentration reached to a critical value. Let this value designate $[\mathrm{C}]_{f}$. There, oxide film began to cover the surface of the melt, and thereafter decarburization curves seemed to behave as the first order with respect to the carbon concentration.

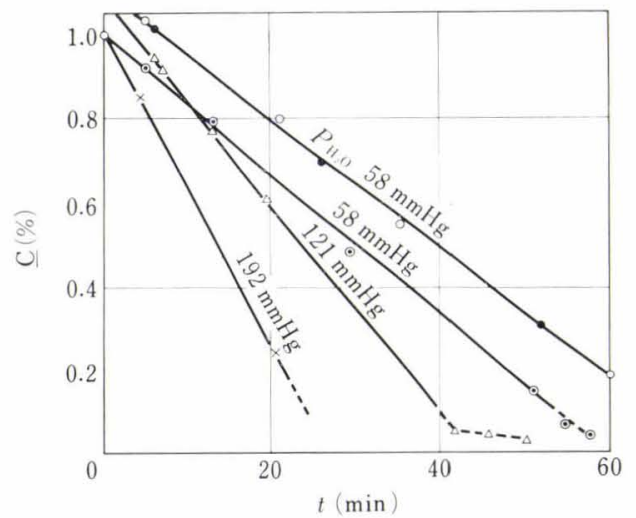

Fig. 2. Decarburization curves at $1600^{\circ} \mathrm{C}$ by argon gas with various $\mathrm{PH}_{2} \mathrm{O}$

Decarburization curves of $\mathrm{Fe}-\mathrm{C}$ alloy with various $\mathrm{CO}_{2}-\mathrm{Ar}$ mixtures were obtained at $1300^{\circ}$ to $1600^{\circ} \mathrm{C}$. Flow rate of gases was taken constant as total $1700 \mathrm{~cm}^{3} / \mathrm{min}$. The rates of the reaction were similar to that of decarburization with $\mathrm{H}_{2} \mathrm{O}$-Ar mixtures as a whole. However, values of $[\mathrm{C}]_{f}$ were far lower than those with $\mathrm{H}_{2} \mathrm{O}$-Ar mixtures.

Next measurements were done on the decarburization of molten alloys containing deoxidizing metallic elements with various $\mathrm{H}_{2} \mathrm{O}-\mathrm{Ar}$ mixtures at $1600^{\circ}$ to $1610^{\circ}$ C. $^{5)}$ The results are shown in Fig. 3. Decarburization curves of Fe-C-Cr alloys had a similar tendency with those of $\mathrm{Fe}-\mathrm{C}$ alloys under the present experimental condition. The values of $[\mathrm{C}]_{f}$ seemed to be almost same or a little higher comparing with

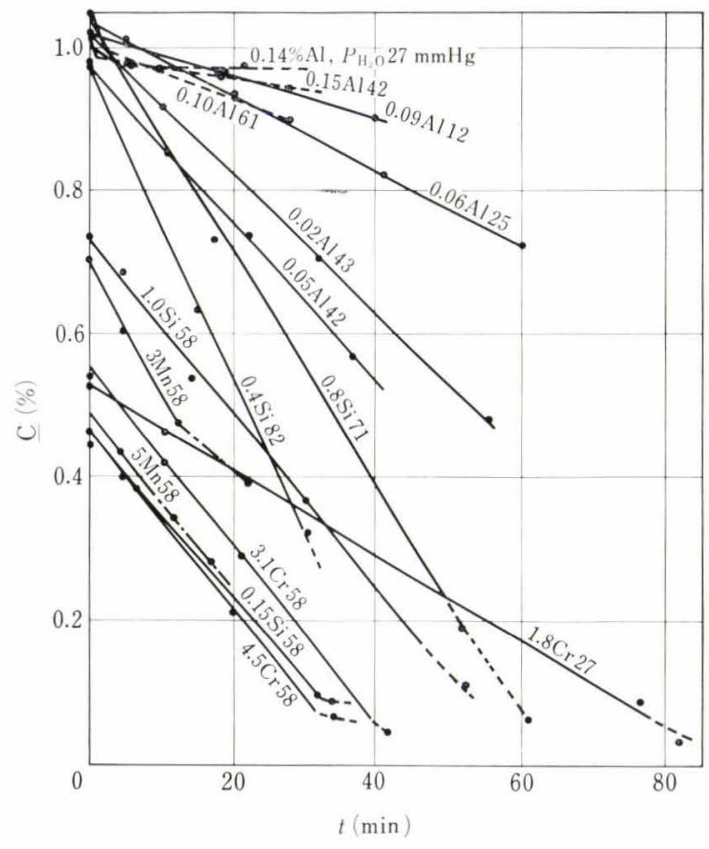

Fig. 3. Effects of alloying elements on the decarburization of iron with various $\mathrm{H}_{2} \mathrm{O}-\mathrm{Ar}$ mixtures at $1600^{\circ}$ to $1610^{\circ} \mathrm{C}$

those in Fe-C alloys. Consequently, it is supposed that the decarburization rate was not affected with the existence of chromium. Oxide on the surface of the melt was solid and a rigid film. However, the oxide film disappeared gradually in spite of the very lowcarbon concentration, when the supply of $\mathrm{H}_{2} \mathrm{O}$ was stopped.

In case of $\mathrm{Fe}-\mathrm{C}-\mathrm{Si}$ alloys, the rates of decarburization were also same as those in Fe- $\mathrm{C}$ alloy until oxide appeared on the surface. The oxide was a liquid film flowing on the surface of the melt, and appeared at a considerably high-carbon concentration comparing with those in Fe-C alloys. After the appearance of oxide films, the rates of decarburization decreased a little but the oxide films vanished away quickly if the supply of $\mathrm{H}_{2} \mathrm{O}$ was stopped. From these observations, it may be concluded that the oxide plays a carrier of oxygen atoms on the metal surface for carbon concentrations less than $[\mathrm{C}]_{f}$.

In case of $\mathrm{Fe}-\mathrm{C}-\mathrm{Mn}$ alloys, decarburizations were carried out as well as those above mentioned, but the values of $[\mathrm{C}]_{f}$ were devoid of reproducibility. At highcarbon concentration, oxide particles began to flow on the surface of the melt, but these particles were manganese oxide formed by the gaseous reaction between $\mathrm{CO}_{2}$ and manganese evaporated from the melt. Consequently, carbon concentration in which the oxide particles appeared, varied widely in accordance with the initial carbon concentration, and the true value of [C], could not be pointed out. Furthermore, in these alloys, smokes of manganese evaporated from the melt were so dense that it could not be observed whether the oxide films were solid or liquid.

Decarburization curves of $\mathrm{Fe}-\mathrm{C}$ - $\mathrm{Al}$ alloys were very different from those of the other alloys above-mentioned. For aluminum concentration above about 
$0.1 \%$, a solid film of the oxide covered the surface of alloys as soon as the decarburization started, and prevented the further progress of reaction. The surface of metal which the oxidation continued after the oxide appeared, was covered with a grey film, and some of white powder was there. The powder was thought to be mainly $\mathrm{Al}_{2} \mathrm{O}_{3}$, but it may contain iron oxide also since it sometimes turned grey. There were many holes on the oxide film. If the supply of water vapor was stopped after the oxide began to appear, 30 to $50 \mathrm{~min}$ were required for the disappearance of oxide layers. For aluminum concentration below $0.1 \%$, oxide did not cover the metal surface, and decarburization curves were almost the same as those of the other alloys. This might be caused by the lack of oxide, since the amount of aluminum in the melt was too little for the amount of oxide to cover the surface.

More detailed measurements were done on the decarburization of $\mathrm{Fe}-\mathrm{C}-\mathrm{Si}$ alloys using $\mathrm{H}_{2} \mathrm{O}-\mathrm{Ar}$ and $\mathrm{CO}_{2}$-Ar mixtures at $\left.1600^{\circ} \mathrm{C},{ }^{6,}, 7\right) \quad$ Variations of each component in alloys during the reaction are shown in Figs. 4 and 5. Carbon concentration decreased at a constant rate until oxides began to appear on the metal surface, whereas silicon concentration did not decrease at all and oxygen concentration did hardly increase. After oxide covered the metal surface, silicon concentration began to decrease noticeably and oxygen concentration began to increase rapidly. Values of $[\mathrm{C}]_{f}$ were affected with the species and amounts of added element and with the composition of oxidizing gas mixtures as shown in Figs. 6 and 7. On the contrary, the decarburization rate for carbon concentration above $[\mathrm{C}]_{f},-d[\% \mathrm{C}] / d t$, which were estimated from

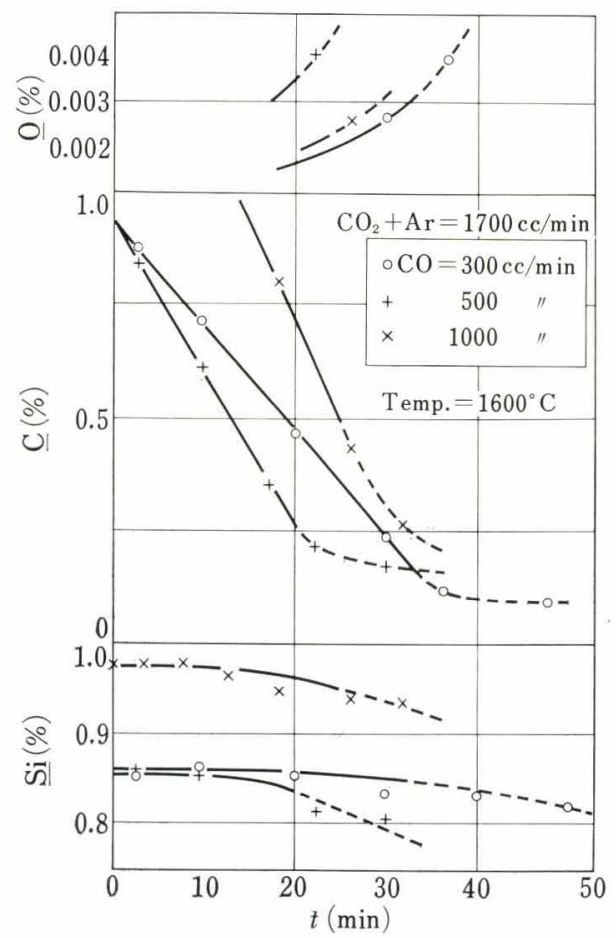

Fig. 4. Decarburization curves by various $\mathrm{CO}_{2}-\mathrm{Ar}$ mixtures at $1600^{\circ} \mathrm{C}$ and variations of silicon and oxygen contents the slopes of reaction curves in their linear ranges, were almost independent of the alloying elements and species of oxidant gas component but those were proportional to the partial pressures of oxidant gas component as shown in Fig. 8. It is supposed from the results in Fig. 8 that the rate determining step in the initial period was principally the transfer of oxidant gas molecules in the gaseous boundary layer on the metal surface.

In each experiment above-mentioned, when the oxidation stopped at the carbon concentration above $[\mathrm{C}]_{f}$, the evolution of $\mathrm{CO}$ bubbles was not observed at all. However, after oxide appeared, many small bubbles evolved from the surface and small iron

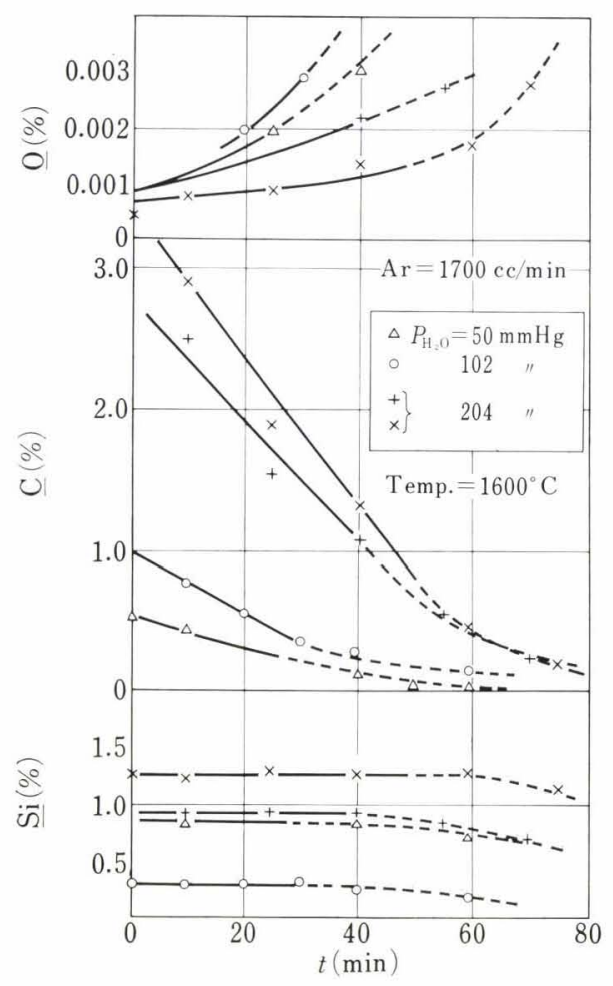

Fig. 5. Decarburization curves by various $\mathrm{H}_{2} \mathrm{O}-\mathrm{Ar}$ mixtures at $1600^{\circ} \mathrm{C}$ and variations of silicon and oxygen contents

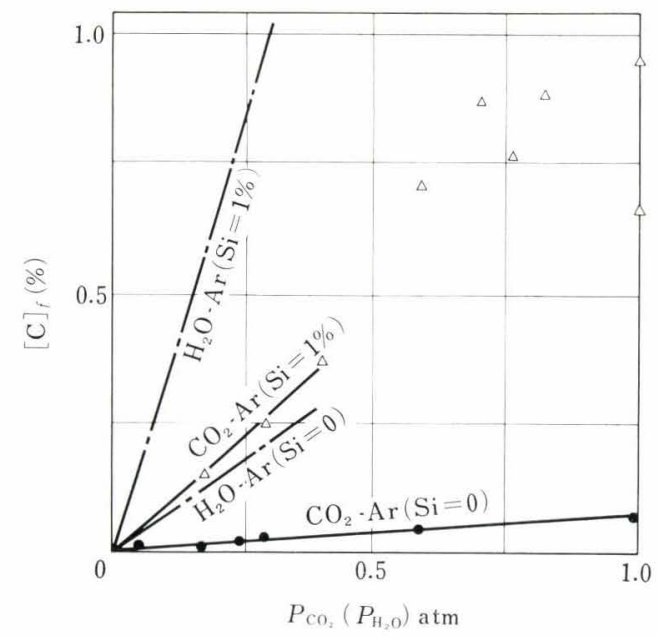

Fig. 6. Relationship between $[\mathrm{C}]_{f}$ and $\mathrm{PH}_{2} \mathrm{O}$ and $\mathrm{PCO}_{2}$ 


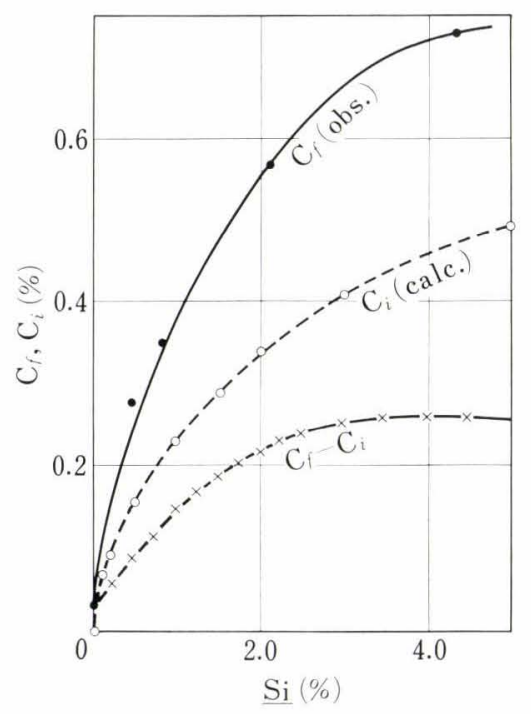

Fig. 7. Relationship between $[\mathrm{C}]_{f}$ and amount of added element $(\mathrm{Si})$

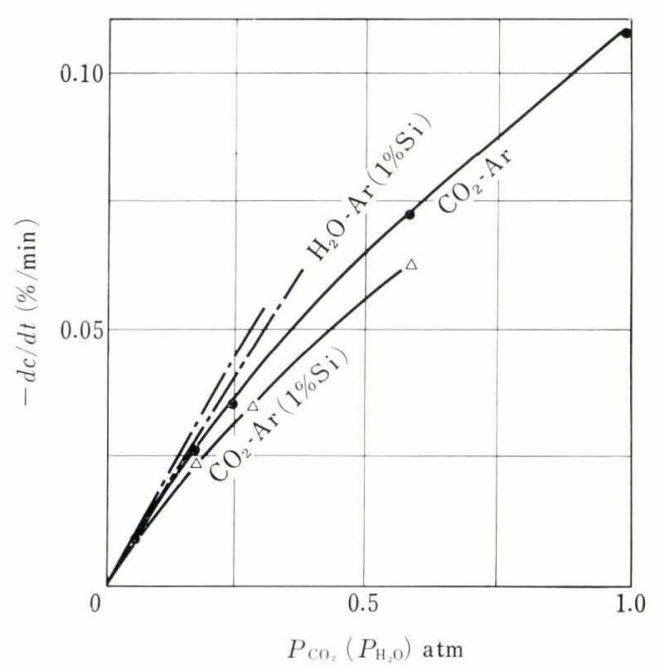

Fig. 8. Relationship between $-d c / d t$ and $P_{\mathrm{CO}_{2}}\left(P_{\mathrm{H}_{2} \mathrm{O}}\right)$

droplets attached on the top of preheating tube and upper part of the crucible. If oxidation was further continued, the evolution of a few large bubbles was observed.

\section{Consideration}

From the temperature dependence of decarburization rate with $\mathrm{H}_{2} \mathrm{O}$-Ar mixtures for carbon concentration above $[\mathrm{C}]_{f}$, the apparent activation energy of the reaction was estimated to be $5.5 \pm 3 \mathrm{kcal} / \mathrm{mole}$. Further, from those with $\mathrm{CO}_{2}$-Ar mixtures in wider temperature range, the activation energy was found to be $6 \pm 2 \mathrm{kcal}$. These small values seem to suggest that the reactions were controlled by diffusion processes. The authors had found previously that the oxidation reaction of liquid iron with $\mathrm{H}_{2} \mathrm{O}$ - $\mathrm{Ar}$ mixtures was a boundary reaction between gas and melt. ${ }^{8)}$ Accordingly, it is also possible that the decarburizations of molten iron with gases are the boundary reactions between gas and melt before oxide phase appeared on the metal surface. On the basis of these facts and observations during and after reactions, the authors had postulated the following model as the mechanism of decarburization with gas. The decarburization with $\mathrm{H}_{2} \mathrm{O}$-Ar mixtures will be considered as examples.

The overall reaction of the decarburization of molten iron with atmosphere is thought to proceed always in several steps. At first, the oxidant molecules, $\mathrm{H}_{2} \mathrm{O}$, is transferred from the bulk of the blown gas mixture to the gas/melt boundary. Assuming that the transfer is caused by diffusion only in the gaseous boundary layer, the rate is expressed by

$$
\frac{d n_{\mathrm{H}_{2} \mathrm{O}}}{d t}=\frac{D_{G}}{\delta_{G}}\left(P_{\mathrm{H}_{2} \mathrm{O}}-P_{\mathrm{H}_{2} \mathrm{O}}^{i}\right)
$$

where $D_{G}$ is the diffusion coefficient of $\mathrm{H}_{2} \mathrm{O}, \delta_{G}$ thickness of the gas boundary layer, and $P_{\mathrm{H}_{2} \mathrm{O}}$ and $P_{\mathrm{H}_{2} \mathrm{O}}^{i}$ the partial pressure of $\mathrm{H}_{2} \mathrm{O}$ in bulk of gas and at the boundary, respectively. In the initial period of reaction, where carbon concentration is sufficiently high, the rate of carbon transfer through the boundary layer of melt from bulk of melt to the phase boundary is far larger than that of $\mathrm{H}_{2} \mathrm{O}$ transfer to the phase boundary. Consequently, the reaction interface is the gas/melt phase boundary, and only the reaction

$$
\underline{\mathrm{C}}+\mathrm{H}_{2} \mathrm{O}(\mathrm{g})=\mathrm{CO}(\mathrm{g})+\mathrm{H}_{2}(\mathrm{~g})
$$

must be taken into account. In accordance with the decrease of carbon concentration, the concentration gradient of carbon in boundary layer becomes small. Therefore, the rate of carbon transfer to the phase boundary decreases step by step, whereas it is readily estimated from the equilibrium constant of reaction (2) that the rate of transfer of $\mathrm{H}_{2} \mathrm{O}$ in gaseous boundary layer remains almost constant. When the rate of carbon transfer decreases to a value smaller than the rate of $\mathrm{H}_{2} \mathrm{O}$ transfer, the reaction interface moves from the phase boundary into the boundary layer of melt. At the same time, the oxygen concentration at the phase boundary begins to increase and at last reaches to its saturation value. As the result, oxide appears on the surface of melt. For some time after oxide layer formed itself, the surface still seemed to be calm. Accordingly in this period of reaction, carbon and oxygen atoms move to the reaction interface respectively through the diffusion layer at each side of the interface, and $\mathrm{CO}$ molecules are formed there. Even if the $\mathrm{CO}$ molecules are removed through the surface of melt to gas phase, it is probable that those cannot grow up to large bubbles because the distance between the reaction interface and phase boundary is very small. As the carbon concentration in melt decreases further, the rate of carbon transfer to the reaction interface becomes so small that oxygen atoms begin entering into iron bulk, and so the reaction interface or region vanishes away. Carbon and oxygen atoms in melt flock by diffusion to active sites at the melt/crucible boundary, where the formation of $\mathrm{CO}$ bubbles proceeds. Thus formed $\mathrm{CO}$ bubbles may reach to the free surface of melt after having some sufficiently large volumes, and be removed off to gas phase. As a result, the surface of oxide layer seems to be foamed 
and the larger iron droplet were found on the upper parts of crucible wall. After oxide appears on the surface of melt, the reaction must take place in two steps as follows:

$$
\begin{array}{r}
\mathrm{H}_{2} \mathrm{O}(\mathrm{g})=\mathrm{H}_{2}(\mathrm{~g})+\underline{\mathrm{O}} \\
\underline{\mathrm{C}}+\underline{\mathrm{O}}=\mathrm{CO}(\mathrm{g}) \ldots
\end{array}
$$

On the basis of these postulations on the mechanisms of decarburization, the rate of reaction can be considered. The rate of reaction for carbon concentrations above $[\mathrm{C}]_{f}$, must be controlled by the rate of gaseous diffusion of $\mathrm{H}_{2} \mathrm{O}$ and be expressed by Eq. (1) as mentioned above. In this period of reaction, however, it is seen from the equilibrium constant of reaction (2) that the partial pressure of $\mathrm{H}_{2} \mathrm{O}$ at the phase boundary, $P_{\mathrm{H}_{2} \mathrm{O}}^{i}$, is always negligibly small. Consequently, changing the variables, Eq. (1) is rewritten as follows:

$$
-\frac{d[\% \mathrm{C}]}{d t}=\frac{D_{G} 1200 F}{\delta_{G} \rho V} P_{\mathrm{H}_{2}}
$$

where $\rho$ is density of iron melt, $V$ the volume of melt, and $F$ the area of gas/melt boundary. This equation is in good agreement with the relation between the rate of reaction and partial pressure of $\mathrm{H}_{2} \mathrm{O}$, given in Fig. 8. The linear velocity of gas stream is different according to localities of the surface of melt. Accordingly the value of so-called $\delta_{G}$ must be different in various localities also. The experiments on the variation of $\delta_{G}$ with experimental conditions will be given elsewhere. Here, the hydrodynamic factors remain constant and so the values of $\delta_{G}$ is simply a mean value at the phase boundary. It is also readily supposed from Eq. (5) that the rate of decarburization is almost independent of the species of oxidant gas component.

Carbon concentration in which oxide appears on the surface of melt, $[\mathrm{C}]_{f}$, will be estimated on the basis of the present model. A schematic pattern of concentrations in the vicinity of phase boundary where a little before oxide appears is shown in Fig. 9. Then assuming that the increase of oxygen concentration at phase boundary can be neglected, and equating the rate at each process to each other, the following relation can be derived: when oxide appears:

$$
\begin{aligned}
-\frac{d[\mathrm{C}]}{d t} & =\frac{D_{G} F}{\delta_{G} V}\left(P_{\mathrm{H}_{2} \mathrm{O}}-P_{\mathrm{H}_{2} \mathrm{O}}^{i}\right) \\
& =\frac{D_{\mathrm{o}} F}{l_{1} V}\left([\mathrm{O}]_{\mathrm{sat}}-[\mathrm{O}]_{e}\right) \\
& =\frac{D_{\mathrm{C}} F}{l_{2} V}\left([\mathrm{C}]_{e}-[\mathrm{C}]_{f}\right) \ldots
\end{aligned}
$$

where $D_{\mathrm{C}}$ and $D_{\mathrm{O}}$ is respectively the diffusion coefficient of $\underline{\mathrm{C}}$ and $\underline{\mathrm{O}}$, and $[\mathrm{C}]_{e}$ and $[\mathrm{O}]_{e}$ is respectively concentration of $\underline{\mathrm{C}}$ and $\underline{\mathrm{O}}$ at the reaction interface. At the phase boundary, assuming that the carbon concentration is equal to zero and that the reaction (3) attains the equilibrium state, the following relation is given :

$$
\frac{P_{\mathrm{H} O}^{i}}{P_{\mathrm{H}_{2}}^{i}}=\frac{[\mathrm{O}]_{\mathrm{sat}}}{K}=k_{f}
$$

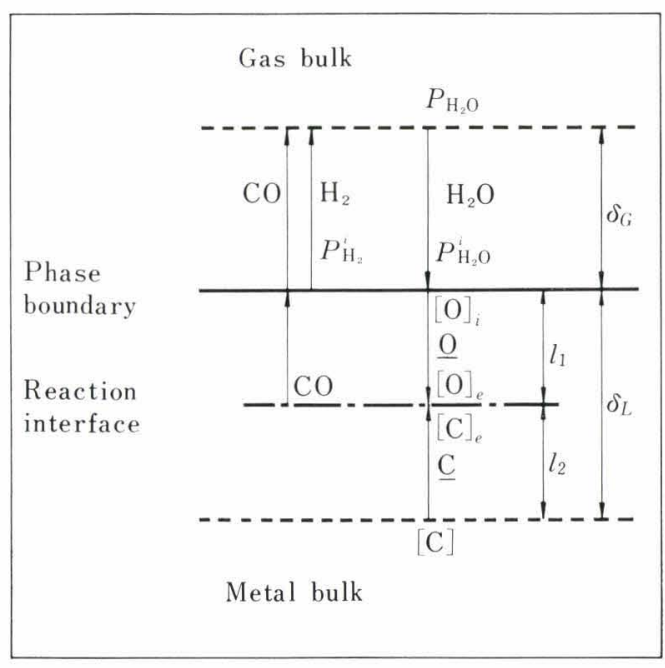

Fig. 9. Schematic pattern of concentrations in the reaction a little before oxide appears on the surface of melt

Further assuming that the total pressure of atmosphere remains constant everywhere, there is following relation between the partial pressures of $\mathrm{H}_{2} \mathrm{O}$ and $\mathrm{H}_{2}$ at the phase boundary,

$$
P_{\mathrm{H}_{2} \mathrm{O}}^{i}+P_{\mathrm{H}_{2}}^{i}=P_{\mathrm{H}_{2} \mathrm{O}}
$$

Although oxygen and carbon concentrations at the reaction interface are unknown, these are assumed here to be negligible respectively against $[\mathrm{O}]_{\mathrm{sat}}$ and $[\mathrm{C}]_{f}$. Combining these relations, the following expression is derived :

$$
\frac{D_{G} / \delta_{G} \cdot 1200 / \rho}{D_{\mathrm{C}} / l_{2}} \cdot \frac{1}{1+k_{f}} P_{\mathrm{H}_{2} \mathrm{O}}=[\% \mathrm{C}]_{f}
$$

It is clear from the reaction model mentioned above that the value of $l_{2}$ must be varied with the change of $[\mathrm{C}]_{f}$. From the range of variation of $[\mathrm{C}]_{f}$ obtained in present experiments, it is thought to be possible that the range of variation of $l_{2}$ is so small that it is assumed to be constant. Accordingly, two fractions in left of Eq. (7) is assumed to be constant at a given temperature and denoted as $k$. So the following relation is derived:

$$
k P_{\mathrm{H}_{2} \mathrm{O}}=[\% \mathrm{C}]_{f}
$$

By means of this equation, the linear relation between $P_{\mathrm{H}_{2} \mathrm{O}}$ and $[\mathrm{C}]_{f}$ shown in Fig. 6 is explained. A similar relation is obtained in the cases of decarburization with $\mathrm{CO}_{2}-\mathrm{Ar}$ mixtures. If the present reaction model is applied to the cases of decarburization with oxygen containing gases, the partial pressure of oxygen at the phase boundary is very small, i.e., of the order of $10^{-8}$ atm. Therefore, by similar approximations, the following relation is derived:

$$
\frac{D_{G} / \delta_{G}}{D_{\mathrm{C}} / l_{2}} P_{\mathrm{O}_{2}}=[\mathrm{C}]_{f}
$$

In this case also, it is clear that the value of $[\mathrm{C}]_{f}$ is proportional to the partial pressure of oxygen in atmosphere. Substituting some reasonable values 
given in other papers to the rate constants and equilibrium constants in Eq. (7), the following relation is derived at $1600^{\circ} \mathrm{C}$.

$$
0.30 P_{\mathrm{H}_{2} \mathrm{O}}=[\% \mathrm{C}]_{f}
$$

From the results given in Fig. 6, it is obtained that $k=0.6$. It may be supposed that this agreement is in a better extent from the validities of numerical values used in above estimation. Since Eq. (7) contains $\delta_{G}$ and $l_{2}$, it is clear that the values of $[\mathrm{C}]_{f}$ are affected by hydrodynamic factors such as the linear velocity of gas stream and stirring of molten iron.

If a deoxidizable metallic element is added to $\mathrm{Fe}-\mathrm{C}$ alloys, the saturation value of $\underline{\mathrm{O}},[\mathrm{O}]_{\mathrm{sat}}$, decreases and then $k_{f}$ decreases. Accordingly, assuming the other numerical values in Eq. (7) remain constant, $k$ increases. Then it is obviously supposed that the stronger the deoxidizability of an added element becomes, the higher $[\mathrm{C}]_{f}$ becomes.

In converter operations, the oxidation of silicon and other metallic elements proceed as soon as the decarburization starts, whereas in present works, the decrease of silicon concentration started until carbon concentration decreased to considerably low values as shown in Fig. 7. Taking silicon as an example of alloying elements, this discrepancy shall be considered thermodynamically. The equilibrium constant $K_{1}$ of the decarburization of molten iron with silica slag:

$$
\left(\mathrm{SiO}_{2}\right)_{\mathrm{sat}}+2 \underline{\mathrm{C}}=\underline{\mathrm{Si}}+2 \mathrm{CO}
$$

can be evaluated from those of the reactions:

$$
\underline{\mathrm{C}}+\underline{\mathrm{O}}=\mathrm{CO} ; \log K=1160 / T+2.003
$$

and $\left(\mathrm{SiO}_{2}\right)_{\text {sat }}=\underline{\mathrm{Si}}+2 \underline{\mathrm{O}} ; \log K=-30720 / T+11.76$. Thus $K_{1}$ is found as follows:

$$
K_{1}=P_{\mathrm{Co}}^{2} \cdot a_{\mathrm{Si}} / a_{\mathrm{C}}^{2} ; \log K_{1}=-28400 / T+15.77
$$

At $1600^{\circ} \mathrm{C}, K_{1}=4$. It is clear from the form of $K_{1}$ that when reaction (9) attains the equilibrium state, the carbon concentration is proportional to $P_{\mathrm{CO}}$. In converter operations, $P_{\mathrm{CO}}$ at the phase boundary must be above $2 \mathrm{~atm}$ in calculations because the oxygen pressure adding its hydrodynamic pressure is 1.4 to $2 \mathrm{~atm}$. On the other hand in present works, $P_{\mathrm{CO}}$ at the phase boundary may be 0.1 to $0.5 \mathrm{~atm}$ because oxidation is carried out by using $\mathrm{H}_{2} \mathrm{O}$ or $\mathrm{CO}_{2}$ diluted with $\mathrm{Ar}$. Consequently it is reasonable that in present works, oxide did not appear until carbon concentration decreased to a sufficiently low value. Relations between $[\mathrm{C}]_{f}$ and silicon concentration are shown in Fig. 10, where the observed points distributed in the region of equilibrium of reaction (9) corresponding to $P_{\mathrm{CO}}=0.3$ to $0.9 \mathrm{~atm}$. However, these values of carbon concentrations are those in iron bulk, and strictly speaking, the values at the phase boundary must be used. It is probable by calculations that the carbon concentrations at the phase boundary are smaller than those in bulk of melt by 0.12 to $0.25 \%$.

It was supposed previously that oxidation of molten steel with air in the ingot practice might be a cause of the formation of non-metallic inclusions. ${ }^{9)}$ It was re-

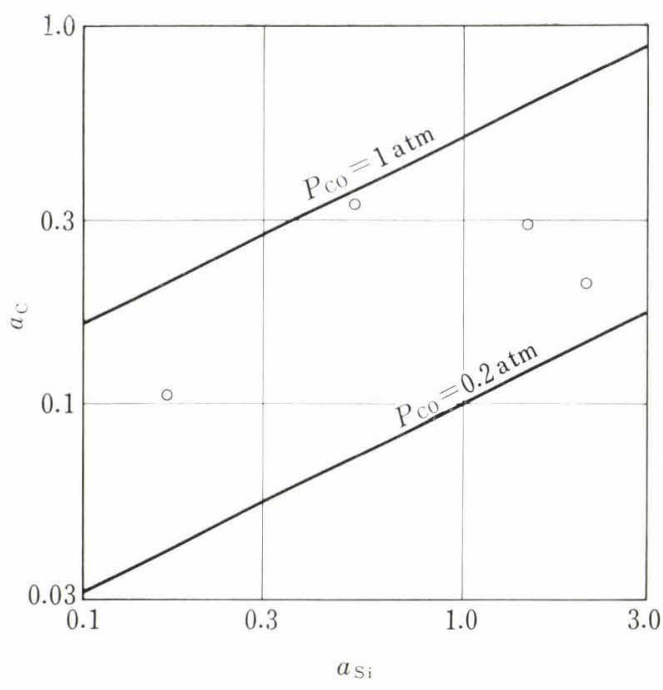

Fig. 10. Relations between silicon and carbon contents when oxide appears. Solid lines express the equilibrium state of reaction (9).

ported that in casting in the air, oxygen concentrations increased in cases of low-carbon 18-8 stainless steel and that large inclusions formed in cases of the steels added by aluminum. ${ }^{10}$ ) On the other hand, it was found that oxidation with air did not affect much on the quality in cases of middle carbon chromium steel. ${ }^{11}$ It is readily seen that these phenomena can be reasonably explained by the model and the rate equations mentioned above. If all the values of rate constants and equilibrium constants were known, it should be possible to estimate the necessity of controlling the atmosphere for a given molten steel to cast.

\section{Conclusions}

The rates of decarburization were measured on molten $\mathrm{Fe}-\mathrm{C}$ and $\mathrm{Fe}-\mathrm{C}-\mathrm{Me}$ alloys with $\mathrm{H}_{2} \mathrm{O}-\mathrm{Ar}$ and $\mathrm{CO}_{2}-\mathrm{Ar}$ mixtures and on the oxidations of coexisting metallic elements. Results are as follows:

(1) Before oxide appears on the surface of melt, the rate of decarburization is proportional to the partial pressure of oxidant gas component, and independent almost of its species and the alloying elements. Accordingly, the reaction seems to be controlled principally by the rate of transfer of the oxidant component from gas bulk to the surface of melt, and is expressed by Eq. (5). Apparent activation energies of these reactions are found to be $5.5 \pm 3$ and $6 \pm 2 \mathrm{kcal}$, respectively.

(2) Carbon concentration where oxide appears on the surface of melt, $[\mathrm{C}]_{f}$, is almost proportional to the partial pressure of oxidant gas component, varied with its species and the amount of added element, and increases according to the deoxidizability of added element. These relations were explained by Eq. (7) which was derived from the model shown in Fig. 9. It was explained thermodynamically that the values of $[\mathrm{C}]_{f}$ obtained in the present works are very low in comparison with those observed in converter steelmaking.

(3) With respect to the possibility of formation of nonmetallic inclusions, the effects of oxidation of mol- 
ten steels with air in casting was estimated by the present results.

\section{REFERENCES}

1) K. Niwa, Y. Watanabe, Y. Itō, S. Maekawa, and Y. Nakagawa: Jap. Soc. Prom. Sci, 19C-4791, (1957, Dec.).

2) T. Fujii : Tetsu-to-Hagané, 46 (1960), 12.

3) K. Itō and K. Sano: Tetsu-to-Hagané, 50 (1964), 873.

4) Y. Gunji, Y. Katase, and Y. Aoki: Tetsu-to-Hagané, 50 (1964), 1828.

5) K. Itō and K. Sano: Tetsu-to-Hagané, 51 (1965), 1252.
6) K. Sano, K. Itō, and S. Arino: Tetsu-to-Hagané, 53 (1967), 777.

7) K. Sano, K. Itō, S. Arino, and T. Takenouchi: Tetsu-toHagané, 53 (1967), 1193.

8) K. Itō and K. Sano: Tetsu-to-Hagané, 49 (1963), 1652.

9) Z. Takao, K. Narita, K. Kanda, and A. Miyamoto: Tetsuto-Hagané, 47 (1961), 1156.

10) T. Sugiyama and G. Katō: Elec. Steelmaking, 33 (1962), 129.

11) S. Oda, H. Hori, K. Mori, and T. Katō: Tetsu-to-Hagané, 50 (1964), 1841. 